Check for updates

Cite this: RSC Adv., 2018, 8, 9112

Received 31st December 2017 Accepted 16th February 2018

DOI: $10.1039 / c 7 r a 13777$

rsc.li/rsc-advances

\section{RGD-modified dihydrolipoamide dehydrogenase conjugated to titanium dioxide nanoparticles - switchable integrin-targeted photodynamic treatment of melanoma cells $\dagger$}

\begin{abstract}
Avraham Dayan, ${ }^{a}$ Gideon Fleminger (D) *a and Osnat Ashur-Fabian*b
The photocytotoxic effect of UVA-excited titanium dioxide $\left(\mathrm{TiO}_{2}\right)$, which is caused by the generation of reactive oxygen species (ROS), is often used in medical applications, such as cancer treatment. Photodynamic-therapy (PDT) is applied in several cancer models including cutaneous melanoma (CM), however the lack of selectivity causing damage to surrounding healthy tissues limits its applicability and novel targeted-delivery approaches are required. As cancer cells often overexpress integrin receptors (e.g. $\alpha v \beta_{3}$ ) on their cell surface, targeted delivery of $\mathrm{TiO}_{2}$ nanoparticles (NPs) via an Arg-Gly-Asp (RGD) motif would make PDT more selective. We have recently reported that the mitochondrial enzyme dihydrolipoamide dehydrogenase (DLDH) strongly and specifically conjugates $\mathrm{TiO}_{2}$ via coordinative bonds. In this work we have modified DLDH with RGD moieties (DLDH ${ }^{R G D}$ ), creating a molecular bridge between the integrin-expressing cancer cells and the photo-excitable $\mathrm{TiO}_{2}$ nanoparticles. Physicochemical assays have indicated that the hybrid-conjugated nanobiocomplex, $\mathrm{TiO}_{2}-\mathrm{DLDH}^{\mathrm{RGD}}$, is producing controlled-release ROS under UVA illumination, with anatase NPS being the most photoreactive $\mathrm{TiO}_{2}$ form. This drug delivery system exhibited a cytotoxic effect in $\alpha \vee \beta_{3}$ integrinexpressing mice melanoma cells (B16F10), but not in normal cells lacking this integrin (HEK293). No cytotoxic effect was observed in the absence of UV illumination. Our results demonstrate the feasibility of combining the high efficiency of $\mathrm{TiO}_{2}$-based PDT, with an integrin-mediated tumor-targeted drug delivery for nanomedicine.
\end{abstract}

\section{Introduction}

Titanium dioxide $\left(\mathrm{TiO}_{2}\right)$ is frequently used in biomedical applications and food technologies due to its high chemical inertness, low toxicity, physical stability and commercial availability. ${ }^{1}$ Upon UV illumination, $\mathrm{TiO}_{2}$ is excited, leading to the production of toxic Reactive Oxygen Species (ROS) $)^{2,3}$ which play important roles in the photocatalytic reaction mechanism. ${ }^{4}$ Photodynamic-therapy (PDT) utilizes ROS production by $\mathrm{TiO}_{2}$ for the treatment of several proliferating skin diseases, ${ }^{5}$ such as vitiligo ${ }^{6}$ and psoriasis, using UVB and UVA radiation. ${ }^{7,8}$ UV illumination of $\mathrm{TiO}_{2}$ nanoparticles (NPs), has been also used for PDT in several types of cancer, ${ }^{9-14}$ including melanoma. ${ }^{15}$ Cutaneous melanoma (CM), which is one of the most rapidly growing cancers worldwide, ${ }^{16}$ is of a serious public health

${ }^{a}$ The School of Molecular Cell Biology and Biotechnology, George S. Wise Faculty of Life Sciences, Israel

${ }^{b}$ The Department of Human Molecular Genetics and Biochemistry, Sackler School of Medicine, Tel Aviv University, Ramat Aviv 69978, Israel. E-mail: gidifl@post.tau.ac.il; osnataf@gmail.com

$\dagger$ Electronic supplementary information (ESI) available. See DOI: $10.1039 / \mathrm{c} 7 \mathrm{ra} 13777 \mathrm{j}$ concern, given the substantial burden associated with the disease.${ }^{17}$ Currently CM is treated by surgery, chemotherapy and radiation therapy as well as targeted- and immuno-therapies. ${ }^{18}$ In cases of advanced melanoma (stages III and IV) PDT may be used, often in combination with surgery ${ }^{19}$ and was shown to regress melanoma metastasis..$^{20}$ However, the lack of specificity towards cancer cells limits the applicability of this approach due to potential damage to the surrounding healthy cells. ${ }^{21}$ This limitation may be overcome by preferentially directing the $\mathrm{TiO}_{2}$ NPs towards cancer cells.

Integrins are a family of cell surface receptors which are overexpressed on tumor cells. Twenty-four integrin heterodimers were identified and consist of a combination between at least 18 $\alpha$-subunits and $8 \beta$-subunits. ${ }^{22}$ These receptors play a key role in the cross-talk between the cell and its surrounding stroma via an Arg-Gly-Asp (RGD) recognition motif and offer a docking site for endothelial, inflammatory and cancer cells. ${ }^{23}$ Integrin $\alpha \mathrm{v} \beta_{3}$ serves as an attractive and a rational target for anticancer drug delivery, ${ }^{24,25}$ including in melanoma. ${ }^{26,27}$ In order to increase the selectivity of PDT towards cancer cells, efforts on developing integrin-targeted drug-delivery tools using $\mathrm{TiO}_{2}-\mathrm{RGD}$ nanocomplexes were recently reported. ${ }^{28}$ We propose an alternative 


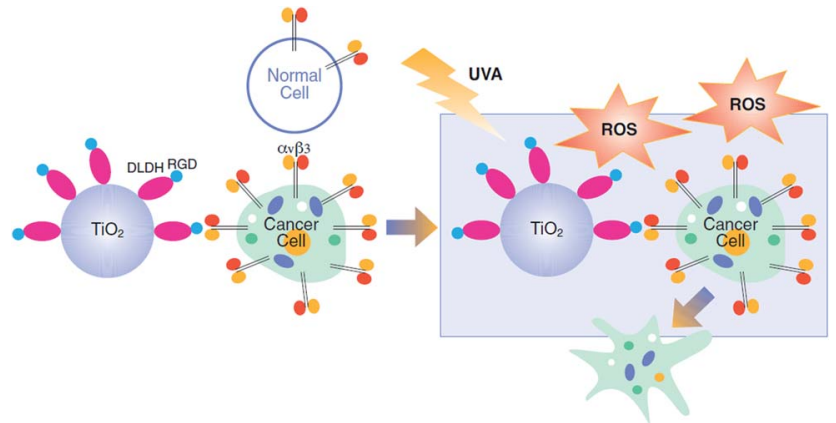

Scheme 1 Integrin-targeted PDT by the nanobiocomplex is switchedon upon UVA illumination.

delivery approach, which is based on the tendency of $\mathrm{TiO}_{2}$ to adsorb to proteins. ${ }^{29}$ Our laboratory has identified the human protein dihydrolipoamide dehydrogenase (DLDH), which strongly and specifically binds $\mathrm{TiO}_{2}$ via coordinative bonds. ${ }^{30-32}$ Bioengineering this protein with RGD moieties and attaching it to $\mathrm{TiO}_{2}$ NPs led to the formation of a hybrid-conjugate nanobiocomplex $\left(\mathrm{TiO}_{2}-\mathrm{DLDH}^{\mathrm{RGD}}\right)$, offering integrin-targeted drug delivery. In this work we present a "switchable" nanomedicine which is activated by UVA illumination to produce ROSdepended cytotoxicity in integrin-expressing melanoma cancer cells, while normal cells with low integrin expression remain less affected (Scheme 1).

\section{Experimental section}

\subsection{Materials}

All reagents and carriers were of analytical grade and were purchased from Sigma-Aldrich (St. Louise, MO), unless otherwise specified. P25 NPs were purchased from Degussa Chemicals (Hanau, Germany).

Tissue culture media and cell lines were purchased from Biological Industries (Bet-Haemek, Israel), unless otherwise specified. B16F10 mouse cutaneous melanoma cells (ATCC, CRL-6475) and human normal embryonic kidney cells, HEK293 (ATCC CRL1573) were cultured in RPMI 1640 medium, supplemented with $10 \%(\mathrm{v} / \mathrm{v})$ heat inactivated fetal calf serum, $2 \mathrm{mM}$ L-glutamine and antibiotics (penicillin/streptomycin), in a humidified atmosphere of $5 \% \mathrm{CO}_{2}$ at $37{ }^{\circ} \mathrm{C}$. The cells were shown to be mycoplasma negative.

\subsection{Cloning}

2.2.1 DLDH. A pET28b-WT-DLD plasmid carrying the mature human DLDH cDNA encoding human DLDH (UniProt accession: P09622, excluding the N-terminal 1-35 signal peptide region), was a generous gift by Prof. Grazia Isaya from the Mayo clinic college (Rochester, Minnesota). It was transformed into competent Escherichia coli (E. coli) BL21 cells. ${ }^{30}$

2.2.2 DLDH ${ }^{\text {RGD }}$. A pET28b-WT-DLD was cleaved with the restriction enzymes NheI and XhoI in order to extract the DLDH. RGD motifs (GRGDSP) were introduced into the $\mathrm{N}$ and $\mathrm{C}$ termini of DLDH by PCR using specific primers (F - TATA GCTAGC
GGTCGTGGTGATAGCCCGGCAGATCAGCCGATTGAT; R -TATA CTCGAG TAATCACGGGCTATCACCACGACCAAAGTTGATTGATTT GCCAAATG, restriction sites are underlined). The PCR products were purified, restricted with NheI and XhoI and ligated into a pET28a $(+)$ expression vector (Novagen, Madison, Wi) using T4 DNA Ligase (New England BioLabs, MA). The plasmid contains an $\mathrm{N}$-terminal hexahistidine $\left(\mathrm{His}_{6}\right)$ tag, which serves as a purification tool. Next, the plasmids were transformed into $\mathrm{CaCl}_{2}$ E. coli competent cells. The bacterial strain, E. coli XL1-Blue, was used for all cloning work while $E$. coli BL21(DE3)pLysS strain was used for subsequent expression of the constructed plasmids. Plates of Lysogeny Broth medium and agar with kanamycin $\left(30 \mu \mathrm{g} \mathrm{ml}{ }^{-1}\right)$ were used to grow single colonies of transformed E. coli at $37^{\circ} \mathrm{C}$ for 16 h. $\mathrm{DLDH}^{\mathrm{RGD}}$ sequence was confirmed by DNA-sequencing as MGSS HHHHHH SSGLVPRGSHMAS GRGDSP [DLDH] GRGDSP.

\subsection{Protein purification}

The expressed His-tagged proteins were isolated by Immobilized Metal Affinity Chromatography (IMAC), on an Ni-NTA column. ${ }^{30}$ DLDH $^{\text {RGD }}$ concentrations were determined by the absorbance at $280 \mathrm{~nm}$ using extinction coefficient of 0.463 calculated from its amino acid compositions using the Expasy ProtParam Program (http://web.expasy.org/protparam).

\section{$2.4 \quad \mathrm{TiO}_{2}$ binding}

Preparation of $\mathrm{TiO}_{2}$ NPs-conjugated $\mathrm{DLDH}^{\mathrm{RGD}}$ was as described before for preparation of the $\mathrm{TiO}_{2}-\mathrm{DLDH}$ complex. ${ }^{30}$

\subsection{Environmental scanning electron microscopy (ESEM)}

ESEM was performed using a Quanta 20 High Resolution (HR) scanning electron microscope, equipped with a Field Emission Gun (FEG) and Energy Dispersive X-ray spectroscopy (EDS), Secondary Electron (SE) - Everhart-thornley and Back-Scattered Electron (BSE) detectors. The $\mathrm{TiO}_{2}$-NPs (rutile, $\mathrm{P} 25$ and anatase) preparations were dispersed in ethanol in an ultrasonic bath for 3 minutes and then applied as droplets to an adhesive $\mathrm{C}$ slices.

\subsection{Illumination}

UVA exposures at $365 \mathrm{~nm}$ (Philips F15T8/BL $15 \mathrm{~W}$ lamp, Amsterdam, Netherland), were for 0-150 min equivalent to $2.7 \mathrm{~J}$ $\mathrm{cm}^{-2}$. Radiation flow was $1.5 \mathrm{~mW} \mathrm{~cm}^{-2}$ as determined by UVA light meter type YK-37UVSD, (Radiometer, Copenhagen, Denmark).

\subsection{Photodegradation}

2.7.1 Methylene blue degradation. Methylene blue (MB) degradation was carried out in a 24 well plate, each well containing $2 \mathrm{ml}$ of $15 \mu \mathrm{g} \mathrm{ml}^{-1} \mathrm{MB}$ and $1 \mathrm{mg}$ of $\mathrm{TiO}_{2}$-NPs (Rutile, P25 or Anatase), stirred with a micro magnetic bar. The wells were exposed to a UVA light source for up to 150 minutes. Dark conditions in the control wells were obtained by covering the wells with aluminum foil. One $\mathrm{ml}$ samples were withdrawn and the $\mathrm{TiO}_{2}$-NPs sedimented by centrifugation (Heraeus, Thermo Fisher Scientific, Waltham, MA) at $17800 \mathrm{~g}$ for 15 minutes. Optical densities of the supernatants $(0.5 \mathrm{ml})$ were determined 
at $663 \mathrm{~nm}$ by a Genesys 10S UV-VIS spectrometer (Thermo Fisher Scientific, Waltham, MA).

2.7.2 Cytochrome $\mathrm{C}$ reduction assay. Cytochrome C (Cyt-C) reduction assay was carried out in a 24 well plate, each well containing $2 \mathrm{ml}$ of oxidized Cyt C solution (0.1 mM of Cyt-C in PBS buffer, pH 7.4) and 0-0.8 mg of anatase NPs (A-NPs), stirred with a micro magnetic bar. The wells were exposed to a light source for up to 30 minutes. Dark conditions in the control wells were obtained by covering the wells with aluminum foil. One ml samples were withdrawn and the A-NPs were sedimented by centrifugation (Heraeus, Thermo Fisher Scientific, Waltham, MA) at $17800 \mathrm{~g}$ for 15 minutes. Optical densities of the supernatants $(0.5 \mathrm{ml})$ were examined at 450 and $550 \mathrm{~nm}$ by a Genesys 10S UV-VIS spectrometer (Thermo Fisher, Waltham, MA, USA) to follow $\mathrm{Fe}^{3+}$ Cyt-C reduction to $\mathrm{Fe}^{2+} \mathrm{Cyt} \mathrm{C}, 1 \mathrm{mM}$ reduced Cyt $\mathrm{C}=23.65$ OD $550 \mathrm{~nm}^{33}$

\subsection{Cellular assays}

2.8.1 Integrin expression. Flow cytometry (MACSQuant, Miltenyi) was used for $\alpha v \beta 3$ evaluation. The cells were harvested in RPMI 1640 and labeled with $10 \mu \mathrm{g} \mathrm{ml}{ }^{-1}$ FITC- $\alpha v \beta 3$ antibody (clone LM609, Merck Millipore, Darmstadt, Germany). Matched isotype IgG served as negative control.

2.8.2 The cytotoxic effect of $\mathbf{T i O}_{2}-\mathrm{DLDH}^{\mathrm{RGD}}$. Cell cultures with 24 well glass-bottom dish (Cellvis, Mountain View, Hercules, CA) of mice melanoma B16F10 cancer cells (50 000 cells per well), in presence of Draq5 (Biostatus, Loughborough, UK), $1 \mu \mathrm{l}$ per well. Normal HEK293 cells served as negative controls (50 000 cells per well). Cells were exposed to UVA light (365 nm) for $1 \mathrm{~h}$ in the presence of $\mathrm{TiO}_{2}$ alone $\left(5 \mathrm{mg} \mathrm{ml}{ }^{-1}\right.$ ), $\mathrm{TiO}_{2}-\mathrm{DLDH}$ (50 $\mathrm{mg}$ protein bound to $5 \mathrm{mg}$ A-NPs) or $\mathrm{TiO}_{2}-$ $\mathrm{DLDH}^{\mathrm{RGD}}$ (50 $\mathrm{\mu g}$ bound protein per $0-5 \mathrm{mg}$ A-NPs). Control wells were covered with aluminum foil to create dark conditions. After $24 \mathrm{~h}$ of incubation, cells numbers were determined by automated cell counter and visualized by confocal microscopy.

2.8.3 Confocal microscopy. Cells were visualized by a fluorescence confocal microscope (Leica, SP5, Mannheim, Germany) with bright field or excitation at $647 \mathrm{~nm}$ and emission at 681-697 nm. The images were obtained using immersion oil ( $\times 63)$ objective. Images constructed using Leica Application Suite Advanced Fluorescence Lite version 2.6.3 build 8173 software.

2.8.4 Absolute cell number determination. The cells were harvested in a fixed volume and counted using an automated cell counter - TC20 ${ }^{\mathrm{TM}}$ (BIO-RAD, Hercules, CA).

\subsection{Statistical analysis}

All data are expressed as means \pm standard error of the mean. Significant differences were assessed by $P$ value.

\section{Results and discussion}

\subsection{Anatase $\mathrm{TiO}_{2}$ NPs is the most photoreactive form}

In this section we aimed to study the $\mathrm{TiO}_{2}$ physicochemical photocatalytic activity in order to define the optimal $\mathrm{TiO}_{2}$ forms which possess the highest surface area and ROS activity of the titanium dioxide molecules. For that, several types of $\mathrm{TiO}_{2}$ (anatase, rutile, amorphous) at different forms (disks, nanotubes, nano-particles) were examined. The different $\mathrm{TiO}_{2}$ preparations were assessed for ROS production using Methylene Blue (MB) photodegradation. Results indicate that the most active $\mathrm{TiO}_{2}$ form is the anatase nanoparticles (A-NPs) (Fig. S- $1 \dagger$ ).

As nanoparticles possess the highest surface areas, and provide advantages due to their small size, permeability, high surface ratio and retention, ${ }^{34}$ we have focused on several $\mathrm{TiO}_{2}$ NPs and compared the photoreactivity of the A-NPs with two additional $\mathrm{TiO}_{2}$ forms, P-25 and rutile nanoparticles upon UVA illumination. For that, two methods were used to measure ROS production, MB photo degradation and cytochrome $\mathrm{C}$ (Cyt C) reduction. The highest rate of $\mathrm{MB}$ degradation (Fig. 1A) was observed with the A-NPs. Photoexcitability of rutile NPs was dramatically lower, while P25 showed an effect that was slightly lower compared to the A-NPs form. Illumination under UVA without Ti-NPs showed very low degree of photolysis. These results are in accord with reports of a higher surface activity of anatase, compared to rutile. ${ }^{35,36}$ To note, light at $365 \mathrm{~nm}$ wavelength was shown to penetrate dipper to the epidermis and dermis, compared to other UV rays ${ }^{37}$ and is therefore suitable for PDT treatments in melanoma cells. ${ }^{37-39}$

Next, we set to measure the A-NPs ROS generation by Cyt C reduction assay under the same illumination conditions. Optimization of A-NPs concentration in the ROS generation assay for $30 \mathrm{~min}$ is shown in Fig. 1B. Based on this experiment $0.4 \mathrm{mg} \mathrm{ml}^{-1}$ of A-NPs was chosen to study the rate of ROS production over time (Fig. 1C). To note, similar ROS production was observed by A-NPs in different buffers, including cell culture media (Fig. S-2†).

\section{2 $\mathrm{DLDH}^{\mathrm{RGD}}$ binding capabilities by different forms of $\mathrm{TiO}_{2}$ NPs}

Many proteins have been found to attach to $\mathrm{TiO}_{2}$ by relatively weak reversible electrostaticlhydrophobic or hydrophobic bonds ${ }^{29,40-42}$ which often results in failure in achieving strong attachment of cells and tissues. ${ }^{\mathbf{4 3 , 4 4}}$

In contrast, we have reported the ability of DLDH to bind $\mathrm{TiO}_{2}{ }^{31,32}$ via strong coordinative bonds. ${ }^{30}$ These strong binding of DLDH to $\mathrm{TiO}_{2}$, has been thoroughly investigated by our group and was shown to be reversed only in the presence of high molar urea concentrations..$^{30-32}$ We have modified DLDH monomer with GRGDSP moieties at the $\mathrm{N}$ - and $\mathrm{C}$-termini, thus creating a dimer of $\mathrm{DLDH}$ with four RGD moieties (DLDH $\left.{ }^{\mathrm{RGD}}\right)$. This GRGDSP sequence was shown to specifically interact with $\alpha \mathrm{v} \beta 3$ integrins. ${ }^{45,46}$ The RGD-modified DLDH is expected to serve as a molecular bridge and facilitate targeted-delivery of $\mathrm{TiO}_{2}$ to integrin-expressing cancer cells. Examination of the amounts of protein bound to $\mathrm{TiO}_{2}$ NPs revealed that comparable $\mathrm{TiO}_{2}$ binding capabilities were observed for DLDH before and after RGD modification.The RGD-modified DLDH is expected to serve as a molecular bridge and facilitate targeted-delivery of $\mathrm{TiO}_{2}$ to integrin-expressing cancer cells. Examination of the amounts of protein bound to $\mathrm{TiO}_{2}$ NPs revealed that 
A

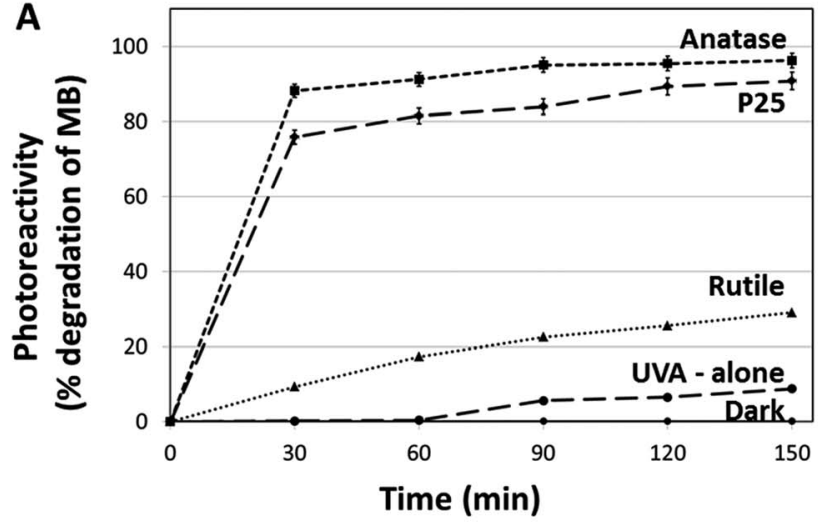

B

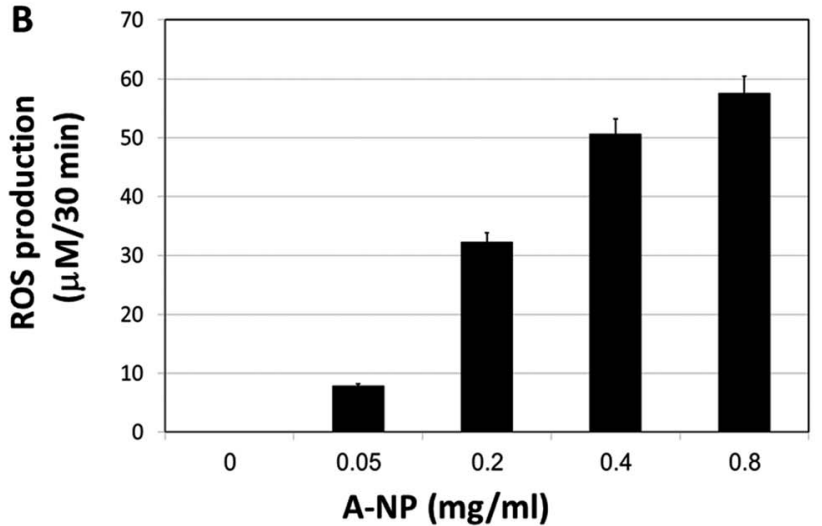

C

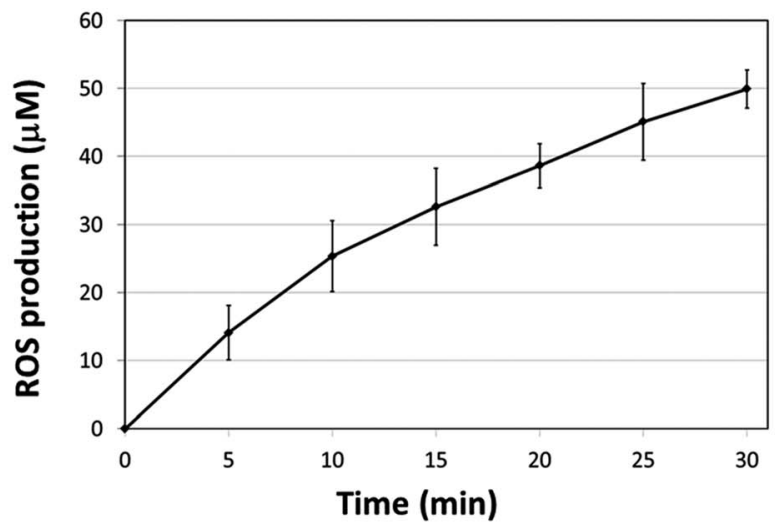

Fig. $1 \mathrm{TiO}_{2}$ nanoparticles photocatalytic activity. (A) Photodegradation of $\mathrm{MB}$ upon UVA illumination by the different preparations of $\mathrm{TiO}_{2}$. (B) ROS production by different amounts of A-NPs after 30 min of UVA illumination. (C) ROS production by a constant amount of A-NPs $\left(0.4 \mathrm{mg} \mathrm{ml}^{-1}\right)$ at different time intervals. Experiments were repeated three times in triplicates.

comparable $\mathrm{TiO}_{2}$ binding capabilities were observed for DLDH before and after RGD modification. We intended to study which of the different $\mathrm{TiO}_{2}$ NPs (A-NPs, rutile and P25) bind DLDH most efficiently. In addition, we aimed to study the effect of the RGD-modification on the binding capabilities of DLDH. The NPs structure of anatase (Fig. 2A), rutile (Fig. 2B) and P25 (Fig. 2C) was demonstrated by ESEM, ranging between 20-90 $\mathrm{nm}$. Examination of the amounts of protein (DLDH or DLDH ${ }^{\mathrm{RGD}}$ ) bound to P25 NPs at different ratios of protein (DLDH, $\mathrm{DLDH}^{\mathrm{RGD}}$ ) to P25 revealed (Fig. 2D) that comparable $\mathrm{TiO}_{2}$ binding capabilities were observed for DLDH before and after RGD modification. At a weight ratio of $10 \mathrm{mg}$ DLDH or $\mathrm{DLDH}^{\mathrm{RGD}}$ per $1 \mathrm{~g}$ of P25 NPs, 90\% binding was observed. Next, the binding of DLDH and DLDH ${ }^{\mathrm{RGD}}$ to the three $\mathrm{TiO}_{2}$ preparations, A-NP, rutile and $\mathrm{P} 25$, were compared at a $1: 100$ ratio of mg protein per $\mathrm{mg} \mathrm{TiO}_{2}$ (Fig. $2 \mathrm{E}$ ) and the amounts of bound non-modified DLDH or RGD-modified proteins were essentially the same. This indicates that DLDH retains its structural conformation and its $\mathrm{TiO}_{2}$ binding site is not hindered by RGD. It is pertinent to note that monomer form of DLDH and DLDH ${ }^{\text {RGD }}$ binds $\mathrm{TiO}_{2}$ (data not shown). Previously, it was calculated that P25 binds DLDH with an apparent $K_{\mathrm{d}}$ of $9.43 \pm$ $1.38 \mathrm{mg}$ DLDH per gram $\mathrm{TiO}_{2}$ and a $B_{\max }$ of $17.15 \pm 0.67 \mathrm{mg}$ bound DLDH per gram of $\mathrm{TiO}_{2}$ which represents about 2000 protein molecules (equivalent to 8000 RGD moieties) bound per $\mu \mathrm{m}^{2}$. Considering the molecular diameter of about $6.7 \mathrm{~nm}$ for the hDLDH dimer and the average pore size reported for P25 $(8.3 \mathrm{~nm})$, the protein is expected to bind mostly to the outer surface of the $\mathrm{TiO}_{2}$ particles. ${ }^{30}$ Taken together, it was shown that A-NPs posess higher photocatalytic activity upon UVA illumination, while retaining $\mathrm{DLDH}^{\mathrm{RGD}}$ binding capabilities. As integrins are highly expressed on the surface of tumor cells, the A-NPs$\mathrm{DLDH}^{\mathrm{RGD}}$ nanobiocomplex may serve as a novel integrin-drug delivery PDT strategy in this disease.

\subsection{Optimization of the A-NPs-DLDH ${ }^{\mathrm{RGD}}$ nanobiocomplex components in mice melanoma cells under UVA illumination or in the dark}

Following the design and characterization of the $\mathrm{TiO}_{2}-$ $\mathrm{DLDH}^{\mathrm{RGD}}$ nanobiocomplex, we aimed to optimize our formulation in vitro for PDT. We used mice cutaneous melanoma cells (B16F10) which highly express integrin $\alpha \mathrm{v} \beta 3$ on their surface. ${ }^{47}$ The cells (50 000 cells/ 24 well plates) were treated with different amounts of A-NPs $\left(0-5 \mathrm{mg} \mathrm{ml}^{-1}\right)$ conjugated to $50 \mu \mathrm{g}$ $\mathrm{DLDH}^{\mathrm{RGD}}$, with increasing $\mathrm{TiO}_{2}$-protein ratios. The cell nuclei are indicated by a red color (Draq5 stain). The cells were incubated with the sediment of the nanobiocomplex for $1 \mathrm{~h}$ in the dark or under UVA illumination (365 nm), following an incubation for an overnight. The cells were incubated for an overnight and the next day were visualized using confocal microscopy. Results show that in the dark the cells remained intact (Fig. 3, upper panel). Following UVA illumination, a substantial amount of nuclear shredding, indicative of apoptosis, was shown with increasing nanobiocomplex ratio (Fig. 3, lower panel). This indicates that UVA illumination is essential for the activation of the nanobiocomplex and suggests that the cells were eliminated by the ROS produced by the photoexcited $\mathrm{TiO}_{2}$-NPs. As described before, excessive ROS can induce cell elimination through several death pathways. The highest cytotoxic effect was observed with $50 \mu \mathrm{g}$ bound $\mathrm{DLDH}^{\mathrm{RGD}}$ to $5 \mathrm{mg}$ A-NPs $(1: 100$ ratio), a combination at which we have documented that $90 \%$ of the protein is bound to the $\mathrm{TiO}_{2}$ NPs. These results suggest that at this nanaobiocomplex ratio an optimal integrin-targeted delivery by the $\mathrm{DLDH}^{\mathrm{RGD}}$ of the $\mathrm{TiO}_{2} \mathrm{NPs}$ is documented. Thus, subsequent experiments were conducted with this specific combination. 

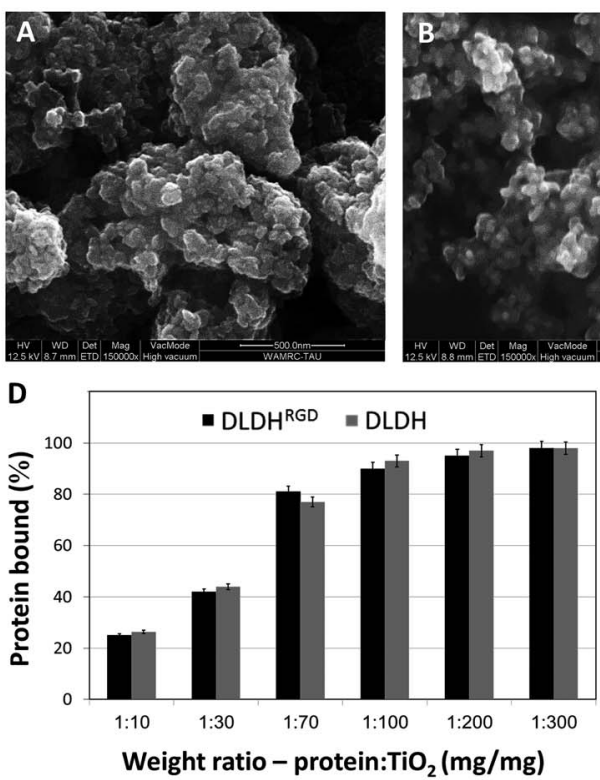
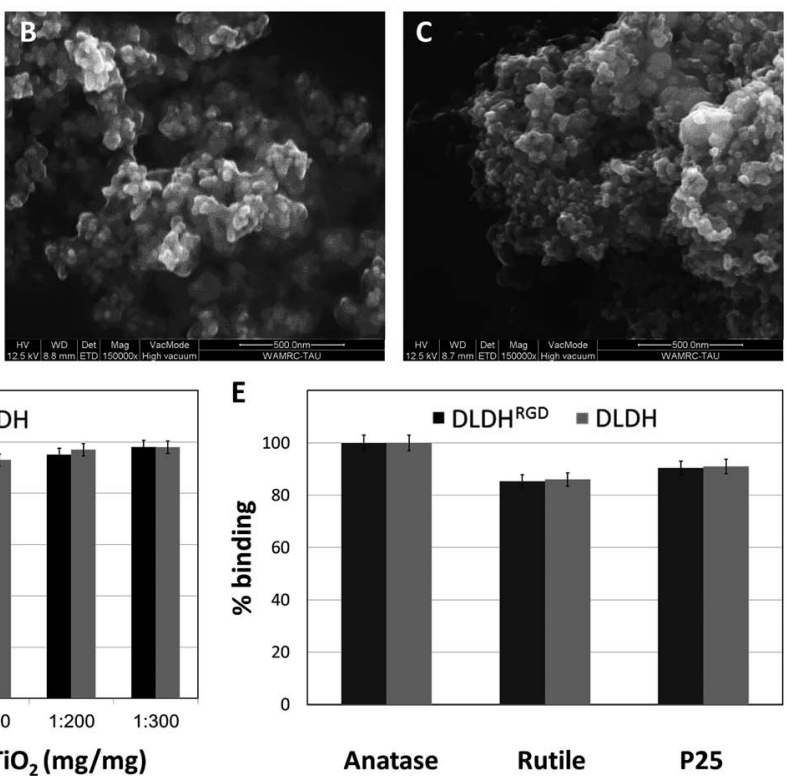

Fig. 2 Structure of $\mathrm{TiO}_{2}$ NPs forms and their binding to DLDH and DLDH ${ }^{\mathrm{RGD}}$. ESEM micrographs of (A) A-NPs (B) rutile NPs and (C) P25-NPs. (D) Comparative binding of DLDH (gray) and $\mathrm{DLDH}^{\mathrm{RGD}}$ (black) to different $\mathrm{TiO}_{2} \mathrm{NPs}$ preparations. (E) Binding curve of DLDH (gray) and DLDH ${ }^{\mathrm{RGD}}$ (black) at a $1: 100$ protein to $\mathrm{TiO}_{2}$ weight ratio. Experiments were repeated three times in triplicates. Average \pm stdev values are shown.

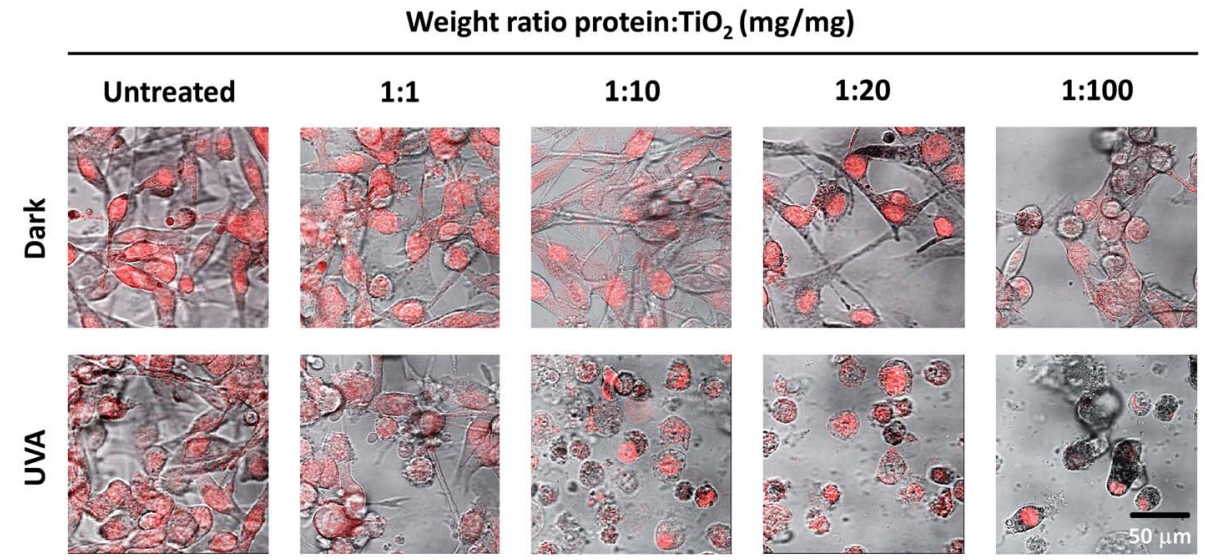

Fig. $3 \mathrm{TiO}_{2}-\mathrm{DLDH}^{\mathrm{RGD}}$ nanobiocomplex induces a cytotoxic effect on B16F10 mice melanoma cancer cells following UVA illumination. The numbers cited in the upper line represent the weight ratio used in the preparation stage. The actual ratio in the nanobiocomplex is presented in Fig. 2D The cell nuclei are stained by Draq5 (red). Merged images of light and red filter are shown using a $63 \times$ objective (fluorescence confocal microscope, Leica SP5). Experiments were repeated twice times in triplicates.

\subsection{The A-NPs-DLDH ${ }^{\mathrm{RGD}}$ nanobiocomplex produces significant cytotoxicity via integrin-targeted PDT}

Lastly, we aimed to validate that the cytotoxic effect that was observed in the cells was directly via integrin-targeted delivery of the A-NPs by the DLDH ${ }^{\mathrm{RGD}}$ protein. For that we have treated B16F10 cells (50 000 cells per 24 well plates) with A-NPs alone $\left(5 \mathrm{mg} \mathrm{ml}{ }^{-1}\right.$ ) and compared this treatment to cells incubated with the optimized weight ratio $(1: 100)$ of A-NPs bound to native DLDH or modified DLDH ${ }^{\mathrm{RGD}}$. The same experimental setting was conducted in normal cells which lack $\alpha \mathrm{v} \beta 3$ integrin expression (HEK293, ${ }^{48}$ Fig. S-3†). The treated cells were illuminated by UVA for an hour. As controls, cells treated in the same manner were kept in the dark. Following illumination, the cells were kept overnight in a biological incubator. The next day, the cells were stained with a nuclear dye (Draq5) and visualized using confocal microscopy. Results indicate that in the absence of photoactivation, no effect on cell density or morphology was observed for all detailed treatments in both the melanoma (Fig. 4A, upper panel) and control cells (Fig. 4A, lower panel). These results indicate that in the absence of illumination, conditions in which $\mathrm{TiO}_{2}$ is not activated, no cytotoxic outcome is anticipated.

Following photoexcitation, A-NPs alone or bound to native DLDH produced a comparable cytotoxic effect in melanoma cells (Fig. 4B, upper panel). Notably, this cytotoxic effect by the A-NPs, was potently enhanced in the presence of the modified 
$\mathrm{DLDH}^{\mathrm{RGD}}$. Regarding the effect observed in the normal control cells (Fig. 4B, lower panel), a comparable cytotoxic effect was documented by $\mathrm{TiO}_{2}$ alone or in the presence of native or RGDmodified DLDH. Next, the same experiment underwent analysis for absolute cell counts under dark conditions (Fig. 4C) or following illumination (Fig. 4D), results correlated with the microscopy data. In details, in the dark, the different $\mathrm{TiO}_{2}$ preparations, namely $\mathrm{TiO}_{2}$ alone, $\mathrm{TiO}_{2}-\mathrm{DLDH}$ or $\mathrm{TiO}_{2}-$ $\mathrm{DLDH}^{\mathrm{RGD}}$, did not affect the cell number of both B16F10 and HEK293 cells. However, illumination of $\mathrm{TiO}_{2}$ or $\mathrm{TiO}_{2}-\mathrm{DLDH}$ by UVA resulted in a comparable $50 \%$ reduction in cell number in both cell lines. In contrast, in the presence of $\mathrm{TiO}_{2}-\mathrm{DLDH}^{\mathrm{RGD}}$ a reduction of over $95 \%$ in the integrin positive cancer cells (B16F10) was shown following illumination. In the normal control cells, which express low integrin levels, 50\% reduction in cell number was documented, which was similar to the effect observed by $\mathrm{TiO}_{2}$ or $\mathrm{TiO}_{2}-\mathrm{DLDH}$. This suggests that the $\mathrm{TiO}_{2}-$ $\mathrm{DLDH}^{\mathrm{RGD}}$ nanobiocomplex is ineffective in the absence of integrins. Taken together, we propose that the photosensitizing cytotoxic effect of $\mathrm{TiO}_{2}$ is greatly enhanced via integrin-targeted delivery.

Several in vitro and in vivo studies, in which $\mathrm{TiO}_{2}$ nanoparticles or nanotubes were assessed as potential anti-cancer treatments were published, mainly in cervical and skin cancers. ${ }^{10-14}$ In all of these works, however, cytotoxicity was induced in up to half of the cells, the value that was obtained by us with $\mathrm{TiO}_{2}$ nanoparticles alone. While using our novel $\mathrm{TiO}_{2}-$ $\mathrm{DLDH}^{\mathrm{RGD}}$ nanobiocomplex, greatly enhanced the cytotoxic effect. In addition, the illumination time needed in our experimental settings to produce an effect was usually shorter. Lastly, it is pertinent to note that the approach of using $\mathrm{TiO}_{2}$ as a single agent is limited by the inability of the $\mathrm{TiO}_{2}$-emitted ROS to distinguish between normal and cancer cells. ${ }^{\mathbf{1 3 , 1 4}}$

In recent years, studies on integrins which, in contrast to normal cells, are highly expressed on the surface of cancer cells, have ignited renewed interest in integrin-targeted-delivery, mainly via the specific recognition site for the three-peptide ligand RGD. ${ }^{49,50}$ By using $\mathrm{TiO}_{2}$ integrin-targeted-delivery, we have produced an effect that was cancer-specific. Similar attempts have been done to selectively deliver the $\mathrm{TiO}_{2}$ particles via an RGD-recognition site. ${ }^{\mathbf{2 8 , 5 1 - 5 5}}$ Other approaches to target the $\mathrm{TiO}_{2}$ directly to cancer cells, sparing harmful effects in normal tissues, are under active research. Such targeteddelivery, for example, includes the attachment of $\mathrm{TiO}_{2}$ to an antibody recognizing colon-cancer specific antigen. ${ }^{56}$ However, most of these $\mathrm{TiO}_{2}$ conjugates require complex synthetic chemical steps.

\section{Conclusions}

The goal of this research was to develop an integrin-targeted nanomedicine for PDT. By modifying $\mathrm{DLDH}$, a $\mathrm{TiO}_{2}$ binding
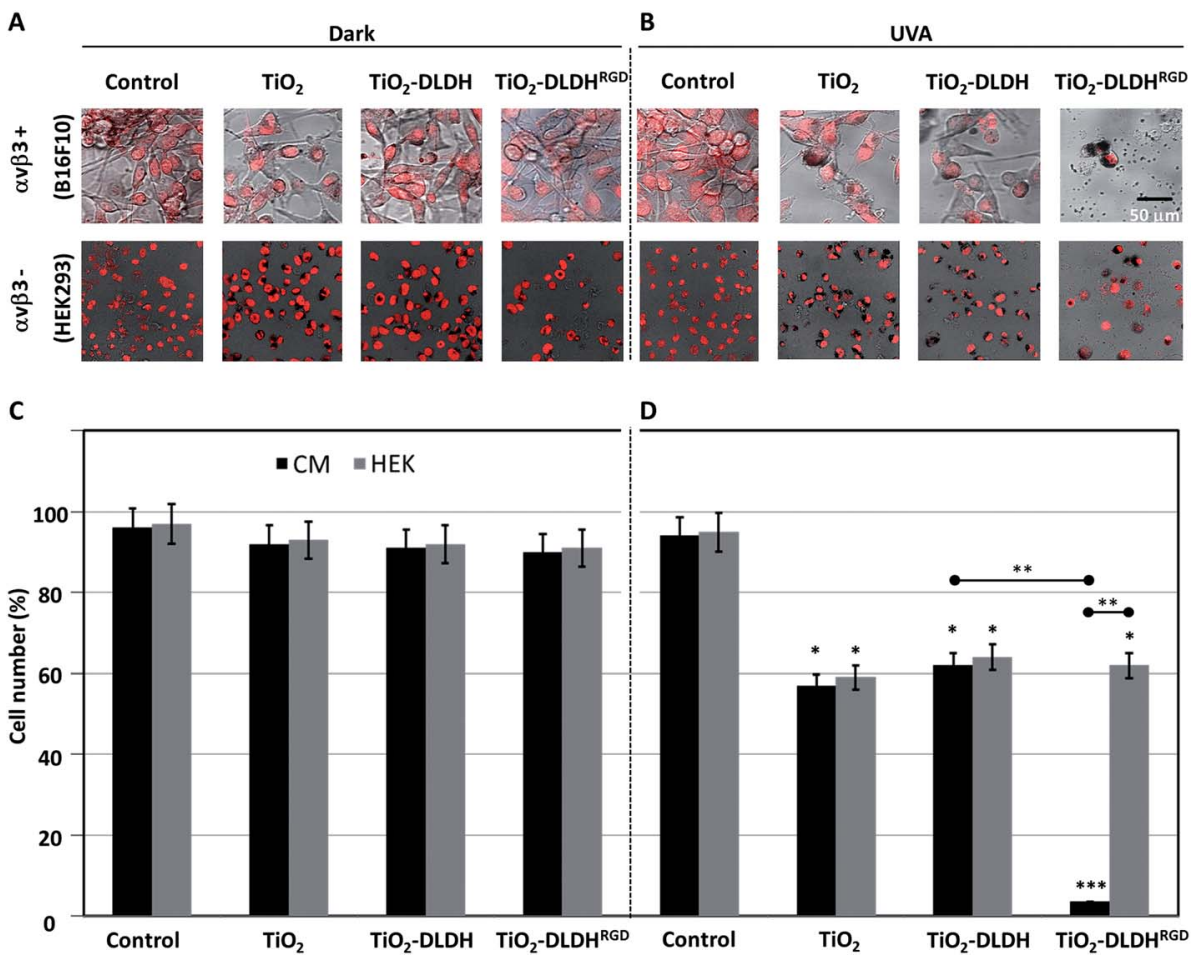

Fig. 4 Cytotoxic effect of the nanobiocomplex (A-NPs-DLDH ${ }^{R G D}$ ) in the presence or absence of UVA illumination. B16F10 or HEK293 cells were treated with $\mathrm{TiO}_{2}, \mathrm{TiO}_{2}-\mathrm{DLDH}$ or $\mathrm{TiO}_{2}-\mathrm{DLDH}^{\mathrm{RGD}}$ and assessed after an overnight by confocal microscopy (Leica SP5) under (A) dark conditions or (B) UVA illumination ( $1 \mathrm{~h}, 365 \mathrm{~nm}$ ). Cells treated in medium lacking $\mathrm{TiO}_{2}$ or the DLDH forms, served as controls. The cell nuclei were stained red (Draq5). Experiments were repeated twice in triplicates. Next the same experiment was analyzed for cell counts under (C) dark conditions or (D) UVA illumination. Experiments were repeated 3 times in triplicates. Significance $(* p<0.05, * * p<0.005, * * * p<0.001)$ from control cells after uva illumination. Significance between the experiments groups $( \pm R G D, \pm \alpha v \beta 3)$ are indicated by an horizontal line. 
protein, with RGD moieties, we have generated a nanobiocomplex that is UVA switchable, highly selective towards cancer cells and effective in producing cell death. We propose that this hybrid-conjugate $\mathrm{TiO}_{2}-\mathrm{DLDH}^{\mathrm{RGD}}$ may serve as a novel targeted therapeutic agent with relevance to several integrinexpressing tumor models.

\section{Conflicts of interest}

The use of DLDH for cancer treatment is protected by a patent in which A. D., G. F. and O. A. F. are the inventors.

\section{Acknowledgements}

This research was supported by the Israeli Ministry of Economics (Projects 52679 and 55869). The authors wish to express their gratitude to Dr Amir Toren for his valuable advices and assistance in this project and to thank Mrs Ronit Hollander for the graphic assistance and the table of contents illustration.

\section{Notes and references}

1 C. N. Elias, J. H. C. Lima, R. Valiev and M. A. Meyers, JOM, 2008, 60, 46-49.

2 I. Mfouo-Tynga and H. Abrahamse, Int. J. Mol. Sci., 2015, 16, 10228-10241.

3 A. Fujishima and K. Honda, Nature, 1972, 238, 37-38.

4 A. Zaleska, Recent Pat. Eng., 2008, 2, 157-164.

5 D. E. Dolmans, D. Fukumura and R. K. Jain, Nat. Rev. Cancer, 2003, 3, 380-387.

6 B. M. El-Zawahry, D. A. Bassiouny, R. M. Sobhi, E. Abdel-Aziz, N. S. Zaki, D. F. Habib and D. M. Shahin, Photodermatol., Photoimmunol. Photomed., 2012, 28, 84-90.

7 T. Werfel, F. Holiangu, K. H. Niemann, O. Schmerling, F. Lullau, A. Zedler, H. D. Strater and M. Niebuhr, Br. J. Dermatol., 2015, 172, 746-753.

8 W. Lapolla, B. A. Yentzer, J. Bagel, C. R. Halvorson and S. R. Feldman, J. Am. Acad. Dermatol., 2011, 64, 936-949.

9 H. Abrahamse and M. R. Hamblin, Biochem. J., 2016, 473, 347-364.

10 R. Cai, Y. Kubota, T. Shuin, H. Sakai, K. Hashimoto and A. Fujishima, Cancer Res., 1992, 52, 2346-2348.

11 M. Kalbacova, J. M. Macak, F. Schmidt-Stein, C. T. Mierke and P. Schmuki, Phys. Status Solidi, 2008, 2, 194-196.

12 J. W. Seo, H. Chung, M. Y. Kim, J. Lee, I. H. Choi and J. Cheon, Small, 2007, 3, 850-853.

13 K. C. Yoo, C. H. Yoon, D. Kwon, K. H. Hyun, S. J. Woo, R. K. Kim, E. J. Lim, Y. Suh, M. J. Kim, T. H. Yoon and S. J. Lee, Int. J. Nanomed., 2012, 7, 1203-1214.

14 K. M. Ramkumar, C. Manjula, G. Gnanakumar, M. A. Kanjwal, T. V. Sekar, R. Paulmurugan and P. Rajaguru, Eur. J. Pharm. Biopharm., 2012, 81, 324-333.

15 Y. Cheng, Y. Chang, Y. Feng, N. Liu, X. Sun, Y. Feng, X. Li and H. Zhang, Small, 2017, 13.

16 V. Nikolaou and A. J. Stratigos, Br. J. Dermatol., 2014, 170, 1119.
17 G. P. Guy, Jr., D. U. Ekwueme, F. K. Tangka and L. C. Richardson, Am. J. Prev. Med., 2012, 43, 537-545.

18 H. R. Keller, X. Zhang, L. Li, H. Schaider and J. W. Wells, OncoTargets Ther., 2017.

19 I. Baldea and A. G. Filip, J. Physiol. Pharmacol., 2012, 63, 109118.

20 T. Tammela, A. Saaristo, T. Holopainen, S. Yla-Herttuala, L. C. Andersson, S. Virolainen, I. Immonen and K. Alitalo, Sci. Transl. Med., 2011, 3, 69ra11.

21 R. Cai, K. Hashimoto, K. Itoh, Y. Kubota and A. Fujishima, Bull. Chem. Soc. Jpn., 1991, 64, 1268-1273.

22 I. Dijkgraaf, C. B. Yim, G. M. Franssen, R. C. Schuit, G. Luurtsema, S. Liu, W. J. Oyen and O. C. Boerman, Eur. J. Nucl. Med. Mol. Imaging, 2011, 38, 128-137.

23 J. A. Askari, P. A. Buckley, A. P. Mould and M. J. Humphries, J. Cell Sci., 2009, 122, 165-170.

24 Y. Gilad, E. Noy, H. Senderowitz, A. Albeck, M. A. Firer and G. Gellerman, Biopolymers, 2015, DOI: 10.1002/bip.22800.

25 Y. Sun, C. Kang, F. Liu, Y. Zhou, L. Luo and H. Qiao, Drug Dev. Res., 2017, DOI: 10.1002/ddr.21399.

26 E. Petitclerc, S. Strömblad, T. L. von Schalscha, F. Mitjans, J. Piulats, A. M. Montgomery, D. A. Cheresh and P. C. Brooks, Cancer Res., 1999, 59, 2724-2730.

27 I. M. Bachmann, R. G. Ladstein, O. Straume, G. N. Naumov and L. A. Akslen, BMC Cancer, 2008, 8, 362.

28 H. Zhao, M. Wang, P. Zhou, Q. Wang, Z. Zhou, D. Wang, H. Yang and S. Yang, J. Mater. Sci., 2017, 52, 13356-13364.

29 Z. J. Deng, G. Mortimer, T. Schiller, A. Musumeci, D. Martin and R. F. Minchin, Nanotechnology, 2009, 20, 455101.

30 A. Dayan, G. Babin, A. Ganoth, N. S. Kayouf, N. Nitoker-Eliaz, S. Mukkala, Y. Tsfadia and G. Fleminger, J. Mol. Recognit., 2017, 30, e2617.

31 A. Siegmann, A. Komarska, Y. Betzalel, I. Brudo, S. Jindou, G. Mor and G. Fleminger, J. Mol. Recognit., 2008, 22, 138-145.

32 G. Gertler, I. Brudo, R. Kenig and G. Fleminger, Materialwiss. Werkstofftech., 2003, 34, 1138-1144.

33 M. L. Cunningham, J. S. Johnson, S. M. Giovanazzi and M. J. Peak, Photochem. Photobiol., 1985, 42, 125-128.

34 N. Bertrand, J. Wu, X. Xu, N. Kamaly and O. C. Farokhzad, Adv. Drug Delivery Rev., 2014, 66, 2-25.

35 T. Van der Meulen, A. Mattson and L. Österlund, J. Catal., 2007, 251, 131-144.

36 L. Liu, H. Zhao, J. M. Andino and Y. Li, ACS Catal., 2012, 2, 1817-1828.

37 A. Amaro-Ortiz, B. Yan and J. A. D'Orazio, Molecules, 2014, 19, 6202-6219.

38 B. Breiner, K. Kaya, S. Roy, W.-Y. Yang and I. V. Alabugin, Org. Biomol. Chem., 2012, 10, 3974-3987.

39 E. Gemenetzidis, O. Shavorskaya, Y.-Z. Xu and G. Trigiante, J. Dermatol. Treat., 2013, 24, 209-214.

40 Z. Xu, X.-W. Liu, Y.-S. Ma and H.-W. Gao, Environ. Sci. Pollut. Res., 2010, 17, 798-806.

41 F. Y. Oliva, L. B. Avalle, O. R. Cámara and C. P. De Pauli, J. Colloid Interface Sci., 2003, 261, 299-311.

42 S. Sousa, P. Moradas-Ferreira, B. Saramago, L. Viseu Melo and M. Barbosa, Langmuir, 2004, 20, 9745-9754. 
43 D. Rivera-Chacon, M. Alvarado-Velez, C. Acevedo-Morantes, S. Singh, E. Gultepe, D. Nagesha, S. Sridhar and J. Ramirez-Vick, J. Biomed. Nanotechnol., 2013, 9, 1092-1097. 44 L. Vroman, Ann. N. Y. Acad. Sci., 1987, 516, 300-305.

45 P. Schaffner and M. Dard, Cell. Mol. Life Sci., 2003, 60, 119132.

46 T. G. Kapp, F. Rechenmacher, S. Neubauer, O. V. Maltsev, E. A. Cavalcanti-Adam, R. Zarka, U. Reuning, J. Notni, H.-J. Wester and C. Mas-Moruno, Sci. Rep., 2017, 7.

47 R. Rathinam and S. K. Alahari, Cancer Metastasis Rev., 2010, 29, 223-237.

48 E. Shinderman-Maman, K. Cohen, C. Weingarten, D. Nabriski, O. Twito, L. Baraf, A. Hercbergs, P. J. Davis, H. Werner, M. Ellis and O. Ashur-Fabian, Oncogene, 2016, 35, 1977-1987.

49 F. Danhier, A. Le Breton and V. Preat, Mol. Pharmaceutics, 2012, 9, 2961-2973.
50 J. Bolley, Y. Lalatonne, O. Haddad, D. Letourneur, M. Soussan, J. Perard-Viret and L. Motte, Nanoscale, 2013, 5, 11478-11489.

51 G. Valente, N. Depalo, I. de Paola, R. M. Iacobazzi, N. Denora, V. Laquintana, R. Comparelli, E. Altamura, T. Latronico, M. Altomare, E. Fanizza, M. Striccoli, A. Agostiano, M. Saviano, A. Del Gatto, L. Zaccaro and M. C. Curri, Nano Res., 2016, 9, 644-662.

52 M.-L. Yu, M.-F. Yu, L.-Q. Zhu, T.-T. Wang, Y. Zhou and H.-M. Wang, BioMed Res. Int., 2015, 2015.

53 F. Li, Y. Zhao, C. Mao, Y. Kong and X. Ming, Mol. Pharmaceutics, 2017, 9, 2961-2973.

54 J. T. Robinson, S. M. Tabakman, Y. Liang, H. Wang, H. S. Casalongue, D. Vinh and H. Dai, J. Am. Chem. Soc., 2011, 133, 6825-6831.

55 H. Qin, K. Maruyama, T. Amano, T. Murakami and N. Komatsu, Mater. Res. Express, 2016, 3, 105049.

56 J. Xu, Y. Sun, J. Huang, C. Chen, G. Liu, Y. Jiang, Y. Zhao and Z. Jiang, Bioelectrochemistry, 2007, 71, 217-222. 